https://doi.org/10.46344/JBINO.2020.v09i06.29

\title{
ANALYSIS OF PREDICTORS OF CERVICAL CANCER RISK IN THE STATE OF ALAGOAS, NORTHEASTERN BRAZIL.
}

Lorenna Peixoto Lopes' ${ }^{2}$,Isabela Karine Rodrigues Agra' ${ }^{2}$.,Aydano Pamponet Machado '.,David Balbino

Pascoal ${ }^{2}$,José Humberto Belmino Chaves '.,Jorge Artur Peçanha de Miranda Coelho '.,Cristiane Monteiro da Cruz ${ }^{2}$

1. Universidade Federal de Alagoas, Alagoas, Brasil

2. Centro Universitário CESMAC, Alagoas, Brasil

Email:cristhy@gmail.com,

\begin{abstract}
Introduction: Cervical cancer is the third most common cancer in Brazilian women and it correlation with human papilloma virus (HPV) infection is established. Objective: To prov the predictor for cervical cancer in patients admitted to a hospital in northeastern Brazi from January 2017 to June 2018. Methods: Retrospective study of 780 reports to predict th risk factor for cervical cancer in a hospital in the city of Maceio / AL. Results and discussior The present study analyzed factors associated with the development of cervical cancer b HPV, such as: incidence of pregnancy, last menstrual period (LMP), bleeding afte intercourse or menopause, cervical inspection, signs of sexually transmitted diseases (STDs use of intrauterine device (IUD), radiotherapy, contraceptives, hormones, cellular changes atypical and glandular squamous cells. We found a correlation of sexually transmittes diseases with lesions in squamous cells. The chances of STD patients developing atypicc squamous cells are 5 times greater than that of a patient without signs of STD. Conclusior The correlation between sexually transmitted diseases and cervical cancer precursor lesion highlights the need to expand the screening policies for cervical lesions with public STL prevention campaigns, preventing the progression of lesions that progress to cancer.
\end{abstract}

Keywords: cervical cancer. vaginal smear. HPV. cervical lesion. STD. 


\section{INTRODUCTION}

Cervical cancer is the fourth most common cancer among women worldwide and its incidence has increased between 45 and 50 years, with higher mortality after the fourth decade of life. Cervical cancer is a neoplasm that has a slow and progressive evolution. It starts with cervical intraepithelial neoplasms, which are benign, characterizing the pre-invasive phase (WHO, 2020; INCA, 2018). The onset of cervical cancer is asymptomatic and may evolve dyspareunia, leukorrhea, vaginal bleeding and sinusorrhagia. In severe stages, it has been seeing obstruction of adjacent structures causing urine or feces uncontrolled, pelvic and low back pain. The cure rate approaches $100 \%$ the cases when associating preventive actions and early diagnosis This system includes the use of condoms, screening with Pap tests and treatment of lesions in the early stages (SANTOS et al., 2019).

Aging, black race, smoking, non-screening, multiple partners, early sexarche, early menarche and late menopause, low social status and infection with the human papilloma virus 16 and 18 (HPV) are the key risk factors involved in cervical cancer development.

The

cytopathological examination screening allows early treatment of lesions, leading to a better prognosis (INCA, 2018).

The database includes women between 25 and 64 years and women without cervical cytology test for the last 3 years, are registered, included in the tracking and notified. Health units responsible for collection, confirmation, diagnosis and treatment can access the system requesting tests and viewing reports. This mechanism strengthens the control of cervix cancer (INCA, 2018). The primary prevention of this type of injury consists of the use of condoms and immunization against HPV, together with health promotion activities. Secondary prevention is based on early detection, which is achieved by performing an early diagnosis that is, through cytopathological analysis of the uterine cervix, popularly known as the Pap smear. In the public sector, this control is related to management actions and health professionals, through the hierarchical distribution of the Unified Health System (SUS) guided by a care assistance flowchart and clinical protocols and guidelines according to the degrees of pathology evolution. The late cervical diagnosis compromisis woman's life, interfering in family relationships, with considerable social damage, in addition, it generates excessive spending on health systems, leading to high rates of bed occupation (BIM et al, 2010; SANTOS et al., 2019; LOPES E RIBEIRO, 2019).

In order to overcome the difficulties inherent in the cytological screening program, scientists are looking for alternative screening methods, mainly in places with economically deficient populations. Visual inspection of the cervix after application of acetic acid appears to be one of the most promising treatment. Acetic acid has a mucolytic action by causing cellular dehydration and coagulation of intranuclear proteins, decreasing the transparency of the epithelium, with the 
intensity of acetowhitening directly proportional to the severity of the lesion (CORDEIRO et al., 2005).

It is known that the concept that the presence of atypical squamous cells is not an exclusion factor for highgrade intraepithelial lesions (ASC-H). This conception was introduced by the Bethesda System 2001, in the classification of cervical cytology. This nomenclature defines precursor lesions of cervical cancer (INCA, 2016).

The Cervical Cancer Information System (SISCOLO) is an epidemiological tool whose purpose is storage the exams performed in the public network. In 2011, SISCOLO and the National Breast Cancer Control Program (SISMAMA) became part of the Cancer Information System (SISCAN), which has several advantages in monitoring women with altered screening tests, including cytology oncotic. The program performs a standardization of reports and compares results temporally and spatially. Thus the network for the prevention, diagnosis and treatment of cancers, including cervical cancer is connected in one database (INCA, 2016).

Cervical Cancer (CC) is responsible for the death of 5,430 women in Brazil with an estimated risk of 15.85 cases per 100,000 women, especially in developing countries, affecting mainly women of social levels. diminished economic and, predominantly nently, in the productive phase of their lives (LOPES e RIBEIRO, 2019; LOBO et al., 2018).

The primary outcome of this research is to evaluate the data collected by SISCAN and correlating the impact between clinical history and results onto patients profiles who seeks at the Professor Alberto Antunes University
Hospital gynecological consultation service. In addition to establishing the characteristics of cervical lesions that predict malignancy, leading to cervical cancer, in patients treated at the HUPAA, from January 2017 to June 2018 with data collected in the Information System of Cancer (SISCAN).

\section{METHODS}

This is a retrospective observational study conducted at the Professor Alberto Antunes University Hospital (HUPAA) based in Maceio / Alagoas in northeastern Brazil from January 2017 to June 2018. 780 electronic reports were analyzed from the comparative analysis of SISCAN to show the profile of patients seeking the HUPAA service. The research was approved by the Ethics and Research Committee of the Federal University of Alagoas under the number of CAE 04243518.1.0000.5013, with the waiver of the Informed Consent Form.

The datawere obtained by accessing the SISCAN Platform using information filter for the given period. In the present study, there was no exposure of patients during cytologies data obtained available in the system.

Patients performed cytology exam from January 2017 to June 2018 with more than 40 years with supposed sexual activity were included in this study. Patients registered with uncomplete data were excluded.

Statistical analysis was performed using SPSS version 25 from descriptive (frequency, percentage, mean and standard deviation) and inferential (chi-square). Chi-square is a non-parametric test that identifies association between two categorical 2020 November Edition | www.jbino.com | Innovative Association 
variables. A logistic regression analysis was performed finding whether the risk factors explain the presence of atypical squamous cells. In addition, odds ratio was reported, measuring the strength of the association between the presence of a reason and the occurrence of an event. For this measure, the size of the effect considered was: $<1.5$ $=$ "trivial", $1.5=$ "small", $3.5=$ "medium" and $9=$ "large" (GOSS-SAMPSON, 2018). As the sample is not probabilistic, that is, convenience, all 780 medical records of patients up to 40 years old who were in the gynecology sector of Hospital Universitário Prof. Alberto Antunes HUPAA-UFAL in the city of Maceió, Alagoas, Brazil..

\section{RESULTS AND DISCUSSION}

According to table 1 , it can be seen that the mean age of the study patients was 30 years without using the IUD with the use of another contraceptive method.

The cervical cancer incidence has increased considerably in several regions of Brazil in young women. Most cases are associated with HPV infection persistence (INCA, 2016). In the present study, the average age of patients with cytopathological changes was 30.3 years. The age group with the highest number of cellular changes was less than 25 years. According to data in the literature, squamous atypia of undetermined significance is the most common epithelial abnormality diagnosed in smears stained by the Pap smear and represents up to $10 \%$ of the results processed in cytology laboratories. In relation to the reports with cytological changes in this study, a predominance of atypia of undetermined significance
(ASC-US) was observed, shows that Table 1, representing 73 (9.3\%) patients. These changes were more prevalent in younger women, with a greater some cases in patients under 25 years of age.

At HUPAA, the percentile of cervical cytology diagnosed with ASC-US was $9.4 \%$, given in Table 1 , in the exams collected from 2017 to 2018. As in the study by Solomon et al., (2001) who found an ASC rate -US between $4.4 \%$ and in the study Hudges et al., (2002), Which found $5 \%$ in all cytological diagnoses. As a criterion for exam quality, the frequency of cytological findings from ASC-US should not exceed two to three times that of low-grade intraepithelial lesion or $9 \%$ in reference centers for cervical or oncological pathology. It is believed that this rate of ASC-US diagnoses, around $9.4 \%$, in our HUPAA service is due to diagnostic difficulties, possibly due to errors in the collection and reading of cytological slides and the limitations of health services, which leads us to question the effectiveness of screening with oncotic cytology. To mitigate the factors that generate these failures, the diagnostic accuracy of the Pap smear must be guaranteed with quality control activities, to allow success in the early detection and treatment of cervical lesions.

Pereira et al., (2006) evaluated the performance of public health laboratories in the state of São Paulo involved in External Quality Monitoring (MEQ) and the applicability of this quality control method in the Unified Health system (SUS). Of the 67,954 cases analyzed in the period between 2000 and 2004, there was diagnostic disagreement in $9,641 \quad(14.2 \%)$ cases. The total of in 9,641 (Innovative Association 
atypical epithelial changes observed in the studied period was $21.5 \%$, distributed in the ASCUS / AGUS categories, 8.8\%, LSIL, 9.1\%; HSIL, 3.2\%; and invasive injuries, $0.4 \%$. The percentage of disagreement in the ASCUS / AGUS diagnostic category in 2000 was $32.3 \%$, with a reduction to $19.2 \%$ in 2004 . The same occurred with the diagnoses of LSIL, HSIL and invasive lesions with respective values of $20,6 \%$, to $6.3 \%, 27.1 \%$ to $10.6 \%$ and $31.7 \%$ to $11.5 \%$.

MEQ evaluations should be used by public network laboratories to make internal quality control strategies and improve technical preparations, through training in collecting, fixing and coloring samples, thus resulting in a reduction in false negative results rates , as well as guaranteeing quality to the laboratories that offer services to the Unified Health System.

Several studies prove the correlation between sexually transmitted infections and the increased risk of developing cervical cancer. The same applies to the analysis carried out in this study, of the limits evaluated, shows that Table 3, which showed a correlation with cell changes in cytology was the presence of STDs. These studies have suggested the

correlation

of genitourinary infection as a cofactor for carcinogenesis. In the analysis of our data, we observed a significant correlation between sexually transmitted disease and high-grade injuries.

It is important to note that, although the sample was calculated as representative of the study population, a prospective longitudinal survey or long-term casecontrol in Alagoas - state of Northeast Brazil - is needed to contemplate more specific tests, such as immunological or immunological methods. molecular biology.

Kos et al., (2004) sought in their clinical analysis to evidence the number and type of cytological abnormality of the cervix and to investigate the relationship of these changes with genital infections, certain agents, such as HPV and C. trachomatis, were more frequent in the group with epithelial dysplasia / carcinoma than in the group control group ( $p<0.05$ in both).

An important finding was the lack of registration of important information, such as risk factors for the appearance of cervical pathologies, in addition to sexually transmitted diseases with the identification of which underlying pathology. We do not have, functionally in our environment, an active patient search system for tracking and monitoring patients with cytological changes, which would probably be more costeffective to the treatment of cervical cancer.As a basis the reimbursement amount for the Papanicolaou test, of $R \$$ 5.37, the amounts reimbursed by SUS for the tests of CH-HPV, cytology in liquid medium and the combination of $\mathrm{CH}$ HPV with conventional cytology, should at most, $\mathrm{R} \$ 19.12, \mathrm{R} \$ 8.22$, and $\mathrm{R} \$$ 11.82, respectively. We do nothave a reference table for molecular biology available on the SUS network; these values would be equal, which shows the difficulty of implementation due to the high cost.

We can consider that one of the pillars for cervical cancer prevention is the serial cytological follow-up and histopathological diagnosis with early surgical treatment. We can have a clear idea of the problem when we consider that HUPAA, as a tertiary service, 
continues with high screening rates, which should be performed in the basic unit, which will refer patients with altered cytology for follow-up and treatment in the tertiary unit. Observing our study results, we can reinforce with the patients the need for primary prevention and the provision of early treatment, avoiding a severe condition of cervical cancer and reducing costs to the health system.

Tables - Analysis of predictors of cervical cancer risk in the state of Alagoas

Table 1. General sample data $(n=780)$

\begin{tabular}{|c|c|}
\hline Feature & $(\mathrm{N}=)$ \\
\hline Age & $30,3 \pm 6,8$ \\
\hline Preventive examination & $482(64,9 \%)$ \\
\hline Uses IUD & $0(0,0 \%)$ \\
\hline Pregnant & $3(0,4 \%)$ \\
\hline Contraceptive & $112(14,4 \%)$ \\
\hline Bleeding after intercourse & $21(2,7 \%)$ \\
\hline Cervical inspection & $147(18,8 \%)$ \\
\hline Tracking & $753(96,5 \%)$ \\
\hline Radio treatment & $38(4,9 \%)$ \\
\hline STI & $18(2,3 \%)$ \\
\hline Candida SP & $6(0,8 \%)$ \\
\hline Cocos & $82(11,1 \%)$ \\
\hline Lactobacilos SP & $412(55,7 \%)$ \\
\hline Atypical squamous cells & $73(9,4 \%)$ \\
\hline Atypical glandular cells & $0(0,0 \%)$ \\
\hline Atypical cells undefined & $0(0,0 \%)$ \\
\hline
\end{tabular}


Table 2. Logistic regression model predicting the presence of atypical squamous cells

\begin{tabular}{|c|c|c|c|c|c|}
\hline \multirow[b]{2}{*}{ Variables } & \multirow[b]{2}{*}{$\boldsymbol{B}(\boldsymbol{E P})$} & \multirow[b]{2}{*}{$p$} & \multicolumn{3}{|c|}{$\begin{array}{c}\text { IC de } 95 \% \text { para } \\
\qquad \operatorname{Exp}(\beta)\end{array}$} \\
\hline & & & LI & $\begin{array}{c}\operatorname{Exp}( \\
\beta)\end{array}$ & $\mathbf{L S}$ \\
\hline Constant & $-2,34(1,07)$ & 0,027 & & & \\
\hline $\begin{array}{l}\text { Preventive } \\
\text { Examination }\end{array}$ & $-0,17(0,26)$ & 0,514 & 0,49 & 0,84 & 1,41 \\
\hline Radio Treatment & $0,14(0,76)$ & 0,854 & 0,25 & 1,15 & 5,17 \\
\hline Contraceptive & $-0,56(0,44)$ & 0,204 & 0,23 & 0,56 & 1,36 \\
\hline $\begin{array}{l}\text { Bleeding after } \\
\text { intercourse }\end{array}$ & $0,78(0,58)$ & 0,179 & 0,69 & 2,19 & 6,87 \\
\hline Cervical Inspection & $0,35(0,29)$ & 0,239 & 0,79 & 1,42 & 2,55 \\
\hline STI & $1,61(0,60)$ & 0,008 & 1,53 & 5,04 & 16,64 \\
\hline Tracking & $0,19(1,05)$ & 0,857 & 0,15 & 1,21 & 9,58 \\
\hline & & \multicolumn{3}{|c|}{$\begin{aligned}(\text { Cox } \& & r^{2}=0,02 \\
\text { Snell }) & \end{aligned}$} & \\
\hline & & \multicolumn{4}{|c|}{ (Nagelkerke) $\quad r^{2}=0,04$} \\
\hline & & \multicolumn{4}{|c|}{$\chi^{2}(7)=13,12, p=0,069$} \\
\hline
\end{tabular}

Table 2 show a logistic regression model demonstrating that the variable has an independent correlation with the presence of atypical squamous cells was signs of $\operatorname{STD}(\mathrm{OR}=5.04 ; 95 \% \mathrm{Cl}=1.53,16.64 ; \mathrm{p}=0.001)$. 
Table 3. Association of presence of atypical squamous cells by STD signs

\begin{tabular}{|c|c|c|c|c|c|c|c|}
\hline & \multicolumn{7}{|c|}{$\begin{array}{l}\text { Presence of atypical } \\
\text { squamous cells }\end{array}$} \\
\hline STI & No & Yes & $\chi^{2}$ & $\mathrm{p}$ & OR & LI & $\mathrm{LS}$ \\
\hline \multirow[t]{2}{*}{ No } & $694(91,1 \%$ & $68(8,9 \%)$ & & & & & \\
\hline & ） & & 5,3 & 0,021 & 3,92 & 1,35 & 11,34 \\
\hline Yes & $13(72,2 \%)$ & $5(27,8 \%)$ & & & & & \\
\hline
\end{tabular}

Through the Chi-square test (with 2x2 continuity correction), an association was identified between STD signs and the presence of atypical squamous cells $[x 2(1)=5.3, p=0.021 ;$ OR $=3.92 ; 95 \% \mathrm{Cl}=1.35,11.34]$.

\section{CONCLUSION}

The results showed the importance of STD prevention programs, stressing the importance of routine cytological examination, of expanding the screening method, capable of detecting precursor lesions.

Research on HPV DNA, associated with oncotic cytology, has been increasingly used in cervical screening studies. Better knowledge of carcinogenic cofactors will allow measures of greater impact on screening and prognosis of cervical lesions.

\section{REFERENCES}

Bim CR, Pelloso SM, Carvalho MDB, Previdelli ITS. Early Diagnosis of Breast and Cervical Cancer in Women in the
Municipality of Guarapuava, PR, Brazil. Rev Esc Enferm USP, vol. 44, n. 04, p. $940-$ 946, 2010.

Cordeiro MR, Costa HL, Andrade RP, Brandão VR, Santana R. Visual inspection of the uterine cervix after application of acetic acid in the tracking of intraepithelial neoplasms and HPVinduced lesions. Rev bras ginecol obstet. 2005 Feb; 27 (2): 51-7.

Goss-Sampson, MA (2018). Statistical Analysis in JasP 0.9.2: A Guide for Students. Version 2, October 2018. (Free PDF)

Hughes SA, Sun D, Gibson C, Bellerose B, Rushing $\mathbf{L}$, Chen $\mathbf{H}$, et al., Managing atypical squamous cells of undetermined significance (ASCUS): human papilomavírus testing, ASCUS subtyping, or follow-up cytology? Am J Obstet Gynecol. 2002; 186(3): 396-403.

INCA. National Cancer Institute Jose Alencar Gomes da Silva. Coordination of Prevention and Surveillance. Division of 2020 November Edition / www.jbino.com | Innovative Association 
Early Detection and Support for Network Organization. Brazilian guidelines for cervical cancer screening / National Cancer Institute Jose Alencar Gomes da Silva. Coordination of Prevention and Surveillance. Division of Early Detection and Support for Network Organization. 2. ed. rev., current. - Rio de Janeiro: INCA, 2016 (a).

Kos M, SARKANJ-GOLUB R, CUPIC H, BALICEVIC D. The correlation of inflammation and epithelial changes in the pap smears of cérvix uteri. Acta Medica Croatica, 59 (4):297-302, dec 2004.

Lobo LMGA, Almeida MM, Oliveira FBM. Cervical Cancer, HPV and Pap smear: A Reflection on the Knowledge of Women. Rev Ciênc \& Saberes, vol. 04, n. 01, p. 889895, 2018.

Lopes VAS, Ribeiro JM. Cervical Cancer Control Limiting Factors and Facilitators: A Literature Review. Cien Sau Col, vol. 24, n. 9. p. 3431-42, 2019.

National Cancer Institute. Coordination of Prevention and Surveillance. Estimate
2018: Cancer Incidence in Brazil [Internet]. 2018. Available at: https://www.inca.gov.br/estimativa/2018 lestimativa-2018.pdf.

Pereira SMM, Ramos DEL, Yamamoto LSU, Shirata NK, Loreto C, Ferraz MGMC et al.,External quality monitoring in cervical cytopathology and the reflection in the routine of public laboratories. STD J Bras Diseases Sex Transm. 2006; 18 (3): 172-7.

Santos ROM, Ramos DN, Migowski Al. Barreirasn Implementation of the Guidelines for the Early Detection of Breast and Cervical Cancer in Brazil. Rev Sau Col, vol. 29, n. 04, e290402, 2019.

Solomon D, Schiffman $M$, Tarone $R$. Comparison of Three Management Strategies for Patients with Atypical Squamous Cells of Undetermined Signifcance: Baseline Results from A Randomized Trial. J Natl Cancer Inst, vol.93, n.4, p.293-299, 2001.

WORLD HEALTH ORGANIZATION. International Agency for Research on Cancer. Globocan. Acess in: 10/02/2020. 